\title{
Effects of the room temperature sensor position and radiator sizing on indoor thermal comfort and energy performances
}

\author{
Jean Pierre Campana ${ }^{1, *}$, Matthias Schuss ${ }^{2}$, Ardeshir Mahdavi ${ }^{2}$, and Gian Luca Morini $^{1}$ \\ ${ }^{1}$ Department of Industrial Engineering (DIN), Alma Mater Studiorum, Bologna, Italy \\ ${ }^{2}$ Department of Building Physics and Building Ecology, TU Wien, Austria
}

\begin{abstract}
In this paper, a simplified zonal model for the evaluation of the spatial distribution of the air temperature in a thermal zone is presented. This model, in which the air flow is caused only by buoyancy forces, is implemented in ALMABuild. The model is used for the analysis of the effect of the temperature sensor positioning on the control system behaviour and on the indoor comfort conditions. This analysis is performed considering a multi-zone building composed by three offices, focusing the evaluation to the central one. The office is heated by means of a radiator in which the hot water flow rate is varied by a valve controlled via a room temperature sensor. By means of numerical simulations, indoor comfort conditions, energy consumptions and control system response are evaluated for three different sensor positions (far from the radiator, in the middle of the office, close to the radiator), two radiator sizes (one obtained by imposing a high supply water temperature, $80{ }^{\circ} \mathrm{C}$, the other a low supply temperature, $60^{\circ} \mathrm{C}$ ) and two control strategies (weather compensation and fast restart). The results presented in this study and demonstrate how complete dynamic energy simulation tools can provide to the designer important information, like the room temperature sensor position that should be close to the emitter and far from cold external walls, for the optimal design of HVAC systems.
\end{abstract}

\section{Introduction}

After the adoption of the Energy Performance of Buildings Directive [1] in 2010, designers are asked to develop buildings which are able to guarantee high comfort conditions but, at the same time, with lower consumptions of primary energy. This ambitious challenge can be achieved only if the designers are assisted by numerical tools able to fully simulate complex energy systems optimized for the reduction of the energy demand and the exploitation of renewable energies. Building Energy Simulation (BES) software are commonly used for studying the dynamic behaviour of each building and HVAC component. In the most diffuse BES software (i.e. TRNSYS [2] and EnergyPlus [3]) each thermal zone is characterized by a single value of the indoor air temperature because, typically, a onenode model is adopted for the evaluation of the convective heat transfer. This unique value of the air temperature coupled to a thermal zone represents the uniform value of air temperature obtained in presence of a perfect air mix; in this way, the spatial distribution of the air temperature within the zone is lost. As a consequence, it becomes impossible to use this software in order to obtain detailed information about the local indoor comfort conditions in a room.

In order to overcome this problem, Computational Fluid Dynamics (CFD) analysis can be coupled to BES software. CFD methods enable to obtain the distribution of the air temperature (and velocity) in the zone by solving the continuum, momentum and energy balance equations, under given boundary conditions, in a number of cells (sub-volumes) in which the zone is subdivided. CFD results give important information about the air flow distribution in a room (i.e. local velocity, turbulence level, temperature and so on). By means of these detailed data one can reconstruct the local comfort conditions in each sub-volume of the zone. However, accurate CFD simulations can be time consuming and, in general, can require high computational costs which become incompatible with complete seasonal dynamic simulations of complex buildings and plants.

For this reason, in the last time, zonal models have been proposed for the local solution of the mass, momentum and energy balance equations in a zone. According to these models, a thermal zone is divided in a limited number of air cells [4]. For each air cell, the governing balance equations, written in a simplified way, are solved with a reduced computational effort by enabling the local calculation of the main air parameters. In literature many zonal models can be found. As an example, Inard et al. [5] used a zonal model with the aim to show the impact of 6 different heater configurations on the temperature field in a room. Nowadays zonal models are implemented in various software, like SIM_ZONAL [6], a tool used for the evaluation of the

\footnotetext{
Corresponding author: Jeanpierre.campana2@unibo.it
} 
thermal comfort and air flow distribution in buildings. As an example, Wurtz et al. [7] used this software for the estimation of the impact on comfort conditions of an electric heater and of a fan-coil. Again, Megri et Yu [8] proposed a zonal model based on an upgraded pressurized model (POMA+) by means of which the effect of three different heater configurations (active surfaces) on the air flow pattern in a room was analysed.

It has to be remarked that in all these works, only the effect of the emitter configuration on the thermal conditions of the room was analysed; the focus was put on the building model and the HVAC system was not taken into account (or modelled in a very simple way). Up to day, BES software able to carry out annual evaluations of the local temperature distribution in a thermal zone and, at the same time, to simulate the dynamic behaviour of a complete HVAC system is rare. In many cases, this can be done only by adopting cosimulation (i.e. coupling different software [9]).

For these reasons, in this paper a "simplified" zonal model is described and implemented in a SIMULINK library called ALMABuild [10]. ALMABuild is a SIMULINK open toolbox which contains the dynamic model of each building element. This library can be easily coupled to ALMAHVAC [11], CARNOT [12] and other SIMULINK open toolbox used for the simulation of HVAC systems with the aim to obtain a complete model of a building-HVAC system.

In this way, a complete analysis of the mutual interactions among emitters, envelope elements and HVAC control system devices can be performed, enabling the evaluation of local comfort conditions and of energy demand for space heating with the adoption of a single software.

In this paper, the adopted zonal model will be used in order to evaluate the impact on the air temperature distribution of the position of the temperature sensor in an office. It is demonstrated that the position of the temperature sensor which control the heat emission in the office influences both indoor thermal comfort conditions and yearly energy consumptions.

\section{Description of the zonal model}

The zonal model adopted in this study and implemented in the ALMABuild library is based on a series of air cells (sub-volumes) in which air is assumed to be perfectly mixed. The air temperature of each cell is obtained by solving a simplified energy balance in which the heat transfer with adjacent cells or building elements through the appropriate contact area is accounted for.

In order to evaluate the heat transfer among adjacent cells, heat transfer coefficients are associated to each contact area (layer). These heat transfer coefficients are calculated starting from a rough estimation of the mass flow among the cells. For each layer $k$ the following energy balance is written:

$$
q_{k}=m_{k} c p\left(\vartheta_{i}-\vartheta_{j}\right)=h_{k} A_{k}\left(\vartheta_{i}-\vartheta_{j}\right)
$$

where $q_{k}$ is the thermal power (W) exchanged between cell $i$ and cell $j$ (divided by the layer $k$ ), $m_{k}$ is the air flow $(\mathrm{kg} / \mathrm{s})$ through the layer $k, c p$ is the specific heat of air $(\mathrm{J} /(\mathrm{kg} \mathrm{K})), \vartheta$ is the cell temperature $\left({ }^{\circ} \mathrm{C}\right), h$ is the heat transfer coefficient $\left(\mathrm{W} /\left(\mathrm{m}^{2} \mathrm{~K}\right)\right)$ linked to the layer $k$ and $A_{k}$ is the contact area between the two cells $\left(\mathrm{m}^{2}\right)$. From equation (1) the heat transfer coefficient can be linked in a simplified way to the air mass flow rate across the layer $k$ as follows:

$$
h_{k}=\frac{m_{k} c p}{A_{k}}
$$

By knowing the specific heat of air and the contact area $A_{k}$, the heat transfer coefficient is known if the air mass flow rate between the cells is known. A simplified momentum balance is written for each layer in order to obtain the air mass flow rate under the hypothesis that the air flow is assumed to be driven only by buoyancy forces (no forced convection) and considering the atmospheric pressure as reference pressure. The expression of the momentum balance varies for horizontal or vertical layers (see Figure 1).

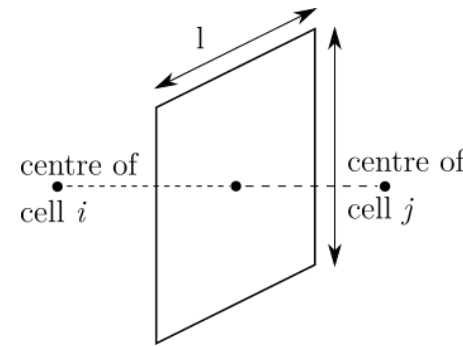

(a)

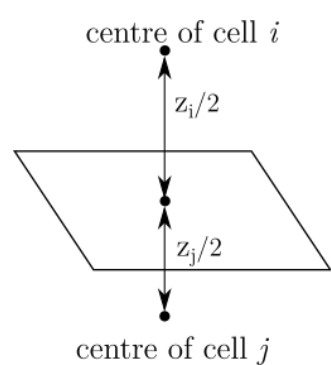

(b)
Fig. 1. Vertical (a) and horizontal (b) layers between cells.

The air mass flow rate across a vertical layer (see Figure 1a) is estimated evaluating the position of the neutral point, which is the point where there is no pressure difference between the adjacent cells. Since only buoyancy forces are here considered, the neutral point is located at the middle height of the layer. In this way, following [4], the air mass flow rate across a vertical layer $k$ can be estimated as follows:

$$
m_{k}=\frac{\left(\rho_{i}+\rho_{j}\right) C_{d} l|\Delta \rho g|^{n}(z / 2)^{n+1}}{n+1}
$$

In equation (3) $C_{d}$ is the discharge factor, set to 0.83 $\mathrm{m} \mathrm{s}^{-1} \mathrm{~Pa}^{-\mathrm{n}}$ as suggested in [4], $l$ is the width of the layer $(\mathrm{m}), z$ is the height of the layer $(\mathrm{m}), g$ is the gravitational acceleration $\left(\mathrm{m} / \mathrm{s}^{2}\right)$ and $n$ is the flow exponent, equals to 0.5 or 1 for laminar or turbulent flow regime respectively [4].

For horizontal layers (Figure 1b) the pressure power law is used for estimating the air flow and the pressure difference between the adjacent cells is calculated by using the Bernoulli's equation:

$$
m_{k}=C_{d} \rho_{i j} A_{k}\left|\frac{\rho_{i} z_{i}-\rho_{j} z_{j}}{2} g\right|^{n}
$$

where $\rho_{i j}$ is the mean air density $\left(\mathrm{kg} / \mathrm{m}^{3}\right)$ in cells $i$ and $j$. The air density in each cell is evaluated according to the perfect gas law; since the reference pressure is assumed to be constant for each cell, the air density depends only on the temperature of the cell. 
The air flow regime (i.e. laminar or turbulent) is estimated evaluating the local value assumed by the Rayleigh number $(R a)$. If the Rayleigh number is lower than $10^{9}$, the flow is considered laminar, otherwise is turbulent, in agreement with [13].

The heat transfer between air cells and building elements (e.g. walls, windows, floors, ceilings...) is evaluated according to the convective heat transfer coefficients reported in the European Standard EN ISO 6946. The overall convective heat transfer between the air cells and a building element is estimated considering the surface temperature of the building element and the mean air temperature $\left(T_{a v, a i r}\right)$ obtained as average value of the air temperature values coupled to all the cells of the zone.

\section{Case study}

The zonal model described in the previous Section, coupled to the detailed radiative model available in the adopted software and described in [14], is used in order to study the effect of the room temperature sensor positioning in a room on the local indoor comfort conditions and on the energy consumptions of the heating system.

The goal of the study is to find if an optimal position for the indoor temperature sensor there exists with the twice scope to maintain adequate comfort conditions in a specific region of the room achieving the lowest energy consumptions.

\subsection{Case study description}

A multi-zone building located in Bologna (Italy), composed by three identical adjacent offices of $25 \mathrm{~m}^{2}(5$ $\mathrm{x} 5 \mathrm{~m}$ ), is considered. Each office is $2.7 \mathrm{~m}$ height and has a double pane window of $1.35 \mathrm{~m}^{2}$ in the South wall, as shown in Figure 2.

The roof is horizontal with a thermal insulation layer (thermal conductivity equal to $0.039 \mathrm{~W} / \mathrm{m} \mathrm{K}$ ) of $6 \mathrm{~cm}$. External walls have got an insulation layer of $8 \mathrm{~cm}$. No insulation is provided for the internal walls which separate the offices; on the contrary, the slab-on-grade floor contains $6 \mathrm{~cm}$ of insulation. The U-values of the office envelope elements are listed in Table 1.

The analysis of energy consumptions and comfort conditions is restricted to Office 2. In Figure 2, the blue central zone of Office 2 represents the area in which comfort conditions have to be optimized.

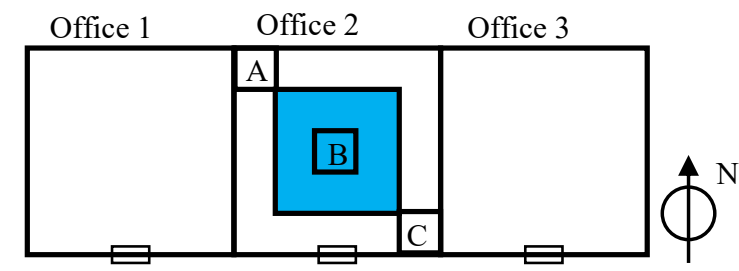

Fig. 2. Plant view of offices. Comfort zone is evidenced in blue, whilst $\mathrm{A}, \mathrm{B}$ and $\mathrm{C}$ refer to the position of the temperature sensor. Radiators are located under the windows.
Table 1. Thermal transmittance (U-value) of building elements.

\begin{tabular}{|c|c|}
\hline & U-values [W/ $\left./ \mathrm{m}^{2} \mathrm{~K}\right]$ \\
\hline External wall & 0.31 \\
\hline Internal wall & 0.99 \\
\hline Floor & 0.27 \\
\hline Roof & 0.42 \\
\hline Window & 1.1 \\
\hline
\end{tabular}

$\mathrm{A}, \mathrm{B}$ and $\mathrm{C}$ in Figure 2 represent three different positions in which the room temperature sensor will be placed. Figure 3 shows the coarse discretization of the room adopted for the definition of the air cells used by the zonal model. Air cells of $1 \mathrm{x} 1 \mathrm{~m}$ in x-y plane (Fig. $3 a$ ), and with different heights (Fig.3b) are adopted.

The room temperature sensor is placed at a distance of $1 \mathrm{~m}$ from the floor and it is contained in the central air cell corresponding to position A, B, C. Position A and C are near to the room walls, whilst sensor B represents an "ideal" sensor position in the middle of the comfort zone.
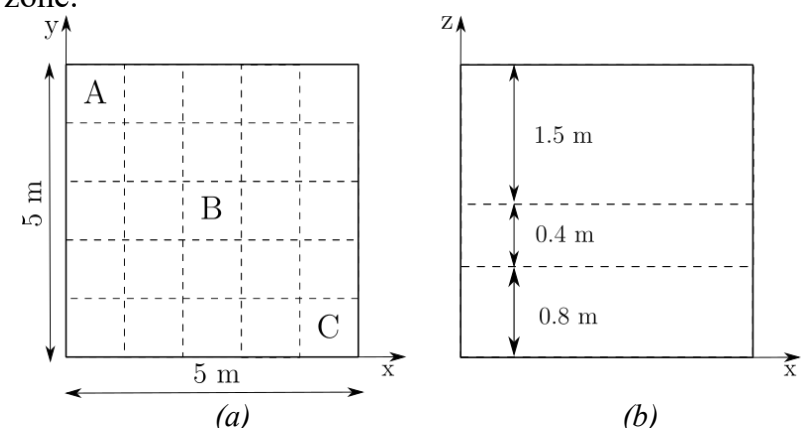

(b)

Fig. 3. Room discretization in air cells, plant view (a) and height discretization (b).

Each room is heated by means of a radiator, located under the window, which releases a thermal power equal to:

$$
\dot{Q}_{\text {rad }}=n_{e l} q_{\text {nom }}\left(\frac{T_{m r}-T_{a v, a i r}}{50}\right)^{r}
$$

where $q_{\text {nom }}$ is the nominal power per element (103 W/element), $r$ is the exponent equal to 1.32 and $T_{m r}$ is the mean temperature of the surface of the radiator. The water content is $1.44 \mathrm{l} / \mathrm{element}$. The heating is activated from 6:00 to 20:00 each day; during the night the heating system is off. The heating system is switched on one hour before people starts to work. For sake of simplicity, in this model when the control system requires heating radiators receive a constant inlet water flow, set to the nominal value, with a variable value of inlet temperature, according to the weather compensation curve.

Cases labelled $R 1$ refer to radiators sized by imposing a temperature difference of $10 \mathrm{~K}$ between inlet and outlet and a nominal inlet temperature equal to 80 ${ }^{\circ} \mathrm{C}$. According to these settings, the radiator is composed by 12 elements $\left(n_{e l}\right)$. The same water flow, and consequently the same temperature difference between inlet and outlet, is considered for cases $R 2$, but the nominal inlet temperature is reduced to $60{ }^{\circ} \mathrm{C}$, leading to radiators composed by 21 elements $\left(n_{e l}\right)$. Both in case $R 1$ and $R 2$, weather compensation is adopted and the inlet 
water temperature is progressively reduced when the outdoor temperature increases. In Figure 4 the weather compensation curves used in simulations for case $R l$ and $R 2$ are shown. For case $F R$, radiators are sized as in case $R 2$, but a fast-restart control is adopted in addition to the weather compensation. The fast-restart consists of an increase of the inlet temperature of the radiators from 60 to $80{ }^{\circ} \mathrm{C}$ during the first hour (from 6:00 to 7:00) after the night interval.

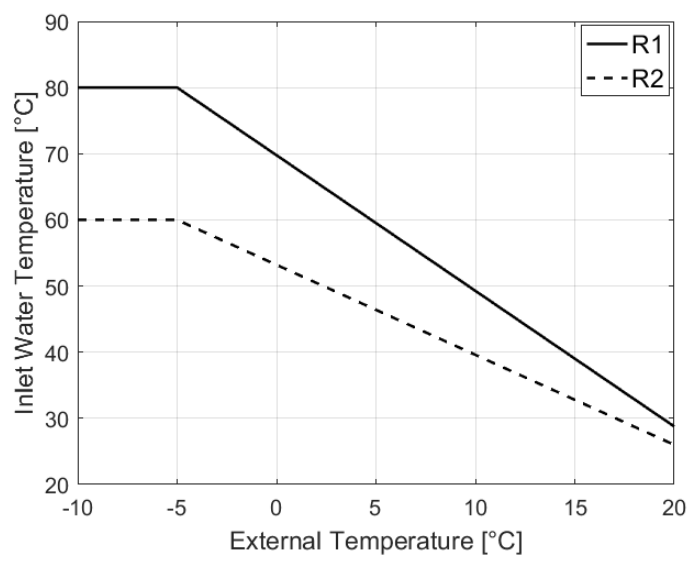

Fig. 4. Weather compensation curve for cases R1 and R2.

Labels $A, B$ and $C$ are used to individuate the room temperature sensor position. In any case, a winter set point of $20^{\circ} \mathrm{C}$, with a dead band of $1 \mathrm{~K}$, is used in order to control the heat emission of the radiators. In order to check the role of the temperature setup value, the set point is moved down from 20 to $19{ }^{\circ} \mathrm{C}$ for case Abis, whilst it is set to $19.25^{\circ} \mathrm{C}$ with a dead band of $0.5 \mathrm{~K}$ for case Atris. Finally, the case Cbis is similar to Abis, but moving the sensor in $\mathrm{C}$, whilst Ctris is the case in which the sensor is in $\mathrm{C}$ with a set point of $20.2^{\circ} \mathrm{C}$ and a dead band of $1 \mathrm{~K}$.

\section{Results}

Numerical simulations have been performed considering the whole heating season starting from October 15 to April 15 by considering the TRY data of Bologna.

The indoor thermal comfort conditions in Office 2 during the winter season are analysed by means of the estimation of:

(i) the comfort time $\left(\tau_{c}\right)$, i.e. the percentage of the winter working time in which the operative temperature (evaluated as the average between the air and the mean radiant temperature) in the blue region of Figure 2 is between 19.5 and $20.5^{\circ} \mathrm{C}$;

(ii) the overheating time $\left(\tau_{o h}\right)$, i.e. the percentage of the working time during which overheating conditions (operative temperature greater than $20.5{ }^{\circ} \mathrm{C}$ ) are observed in the blue region of Figure 2.

The effects on the heating system behaviour are analysed by recording during simulations the following parameters: (i) the mean heating time $\left(t_{o n}\right)$, i.e. the average heating time between two consecutive shutdown of the radiator;

(ii) the mean shutdown time $\left(t_{o f f}\right)$, i.e. the average shutdown time between two consecutives on-cycles;

(iii) the seasonal operating time $\left(t_{o n, y}\right)$, i.e. the total amount of hours in which the radiator is on during the winter;

(iv) the total energy demand $(E)$, i.e. the energy released by radiators to the room.

\subsection{Cases R1: high temperature radiator}

In Figure 5 the cumulative distribution of the mean operative temperature in Office 2 during the whole winter by considering only the working time (7:00-20:00 each day) is shown.

It is possible to observe that the cumulative distribution varies if the position of the room temperature sensor is changed.

Dashed black lines in Figure 5 represent the target band of the operative temperature $\left(19.5-20.5^{\circ} \mathrm{C}\right)$.

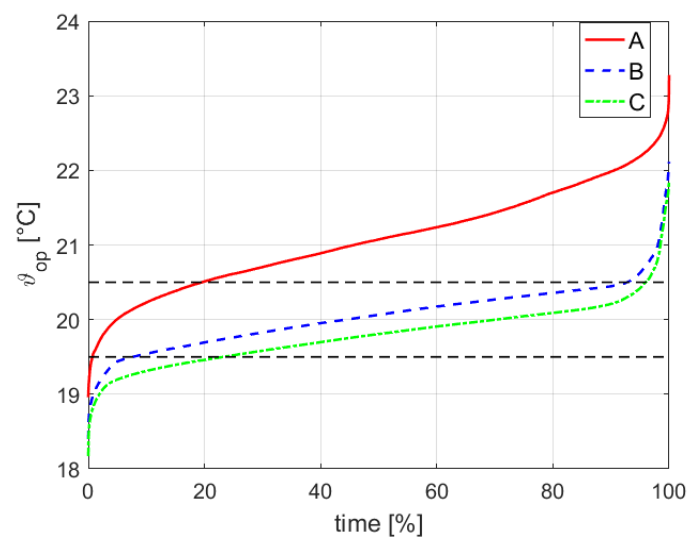

Fig.5. Cumulative distribution of the average operative temperature $\left(\vartheta_{\mathrm{op}}\right)$ in Office 2 for cases R1 as a function of the position of the room temperature sensor.

When the sensor is located in A (solid line) close to the North external wall and far from the radiator, the cumulative distribution of the operative temperature $\left(\vartheta_{\mathrm{op}}\right)$ drops only for $20 \%$ of the winter time within the target band. This means that in this case overheating conditions are frequent.

On the contrary, if the sensor is moved in B (dashed line), i.e. in the middle of the comfort zone, the cumulative distribution of the operative temperature is almost always contained in the target band. Moving the sensor near to the South external wall close to the radiator (position $\mathrm{C}$, dash-dot line), a large portion of the cumulative distribution is still contained into the target band, but in this case undercooling conditions (i.e. operative temperature lower than $19.5{ }^{\circ} \mathrm{C}$ ) appear. It should be noted that the shape of the trend of the cumulative distribution of the operative temperature in case $\mathrm{C}$ and $\mathrm{B}$ is very similar.

The observations deduced from Figure 5 are confirmed by the results collected in Table 2 . In fact, it can be observed that the overheating time becomes 
higher than $80 \%$ if the sensor is placed on the internal wall (A), otherwise the overheating time is less than $10 \%$.

Table 2. Comfort and heating system parameters for cases R1.

\begin{tabular}{|c|c|c|c|c|c|c|}
\hline & $\begin{array}{c}\tau_{\mathrm{c}} \\
{[\%]}\end{array}$ & $\begin{array}{c}\tau_{\text {oh }} \\
{[\%]}\end{array}$ & $\begin{array}{c}\mathrm{t}_{\text {on }} \\
{[\mathrm{min}]}\end{array}$ & $\begin{array}{c}\mathrm{t}_{\text {off }} \\
{[\mathrm{min}]}\end{array}$ & $\begin{array}{c}\mathrm{t}_{\text {on, }} \\
{[\mathrm{hr}]}\end{array}$ & $\begin{array}{c}\mathrm{E} \\
{[\mathrm{kWh}]}\end{array}$ \\
\hline$A$ & 18.8 & 80.7 & 725 & 800 & 2369 & 1635 \\
\hline$B$ & 85.1 & 7.3 & 132 & 263 & 1456 & 1378 \\
\hline$C$ & 72.7 & 4.0 & 94 & 215 & 1265 & 1318 \\
\hline
\end{tabular}

Considering the heating system behaviour, important differences between case A and B-C can be observed. Case A is characterised by the highest mean heating time $\left(t_{o n}\right)$, shutdown time $\left(t_{o f f}\right)$ and seasonal operating time $\left(t_{o n, y}\right)$, which are respectively around $450 \%, 205 \%$ and $62 \%$ greater than case B (ideal case). On the contrary, $t_{o n}, t_{o f f}$ and $t_{o n, y}$ for cases B and $\mathrm{C}$ differ less than $30 \%$.

These results highlight that it is mandatory to avoid placing the room temperature sensor close to cold walls (i.e. North external wall) far from the emitter. On the contrary, sensors close to the emitter on the external wall (like in the case of thermostatic valves coupled to radiators) are able to guarantee a sensible reduction of the values of the overheating time.

In Figure 6 the operative temperature distribution within Office 2 at $1 \mathrm{~m}$ height from the floor when the sensor (identified by the red dot) reaches the upper value of the control band $\left(20.5{ }^{\circ} \mathrm{C}\right)$ is shown. By comparing the distribution of the operative temperature shown in Figure 6 , it can be noted that the operative temperature in correspondence of position $\mathrm{B}$ and $\mathrm{C}$ is very similar to the average temperature of the comfort zone (highlighted by the red rectangle in Figure 6).

On the contrary, the operative temperature in position A is always close to the lowest value in the room. This means that, as it can be seen in Figure 6, when the sensor in position $\mathrm{A}$ measures an operative temperature equal to $20.5^{\circ} \mathrm{C}$, the rest of the room is at higher values of the operative temperature; this fact explains the large values of the overheating time observed in the comfort zone in case A.

The large values of the heating time (about 12 hours) when the sensor is placed in A, which is responsible of the frequent overheating conditions in the comfort zone, is due to the low response time of the heating system.

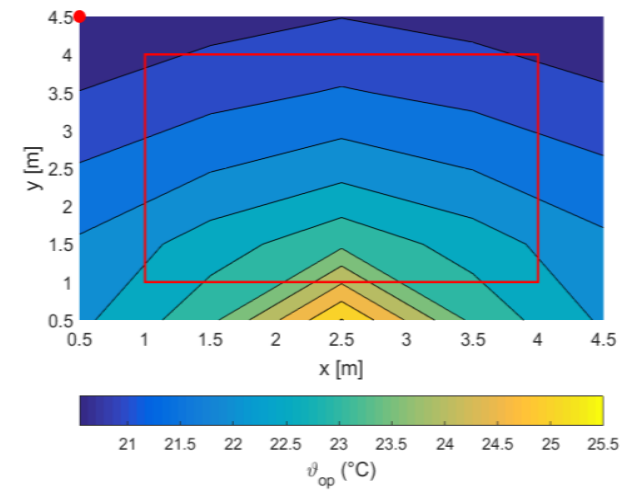

(a)

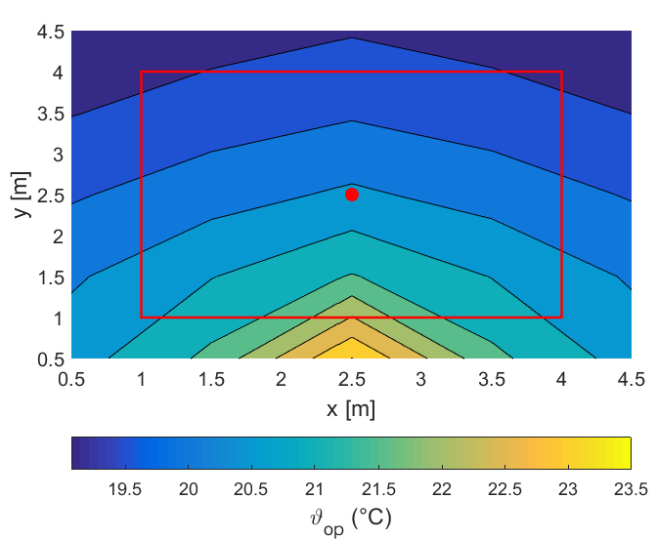

(b)

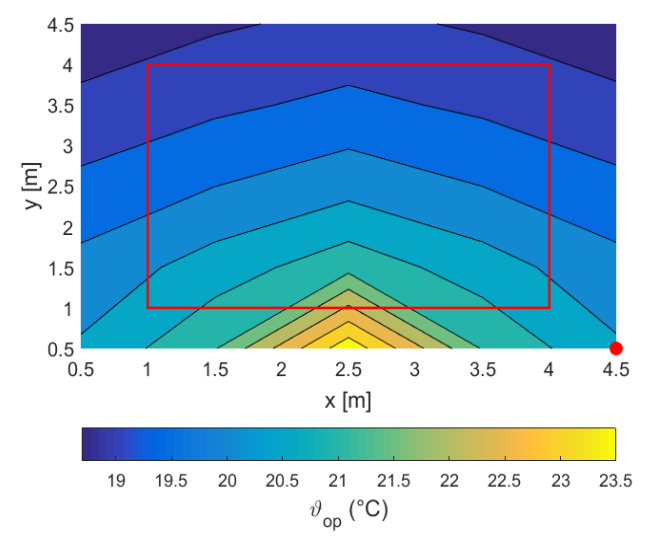

(c)

Fig.6. Operative temperature distribution at $1 \mathrm{~m}$ height from the floor when the sensor reaches $20.5^{\circ} \mathrm{C}$ : (a) sensor in $\mathrm{A}$; (b) sensor in $\mathrm{B}$; (c) sensor in $\mathrm{C}$. Red rectangle evidences the comfort zone.

In fact, as represented in Figure $7 \mathrm{a}$, the operative temperature measured by the sensor in A rises very slowly compared to the temperature in the comfort zone, causing a huge delay of the heating system reactions (about 8 hours for the first day represented in Figure 7a). This behaviour is linked to the combined effect of the distance between the sensor and the emitter and the proximity with a cold external wall. In this case, the operative temperature in position A is strongly affected by the inner surface temperature of the external wall, that rises slowly due to its high thermal inertia.

On the contrary, when the sensor is placed in B or C, the operative temperature measured by the sensor is very close to the average value of the operative temperature in the comfort zone, as shown by Figure $7 \mathrm{~b}$ and Figure $7 \mathrm{c}$, respectively.

Differences in terms of mean heating time $\left(t_{o n}\right)$, shutdown time $\left(t_{\text {off }}\right)$ and seasonal operating time $\left(t_{o n, y}\right)$ between case $\mathrm{B}$ and $\mathrm{C}$ are due to the fact that $\mathrm{C}$ is closer to the emitter than $\mathrm{B}$. The mean heating time in case $\mathrm{C}$ is the lowest because the operative temperature in $\mathrm{C}$ reaches faster the setup value.

Finally, it is possible to appreciate from the data collected in Table 2 how the energy demand is linked to the overheating time. The highest the overheating time, 
the highest the energy demand. For this reason, case $\mathrm{C}$ requires less energy than $\mathrm{B}(-4 \%)$ and $\mathrm{C}(-22 \%)$.

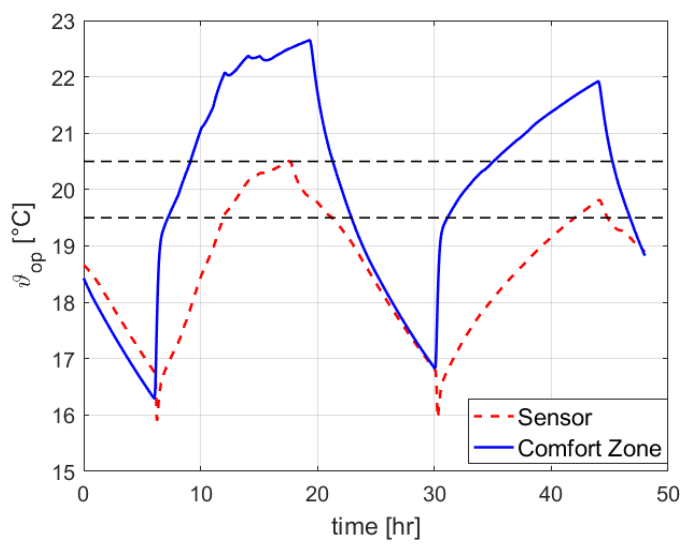

(a)

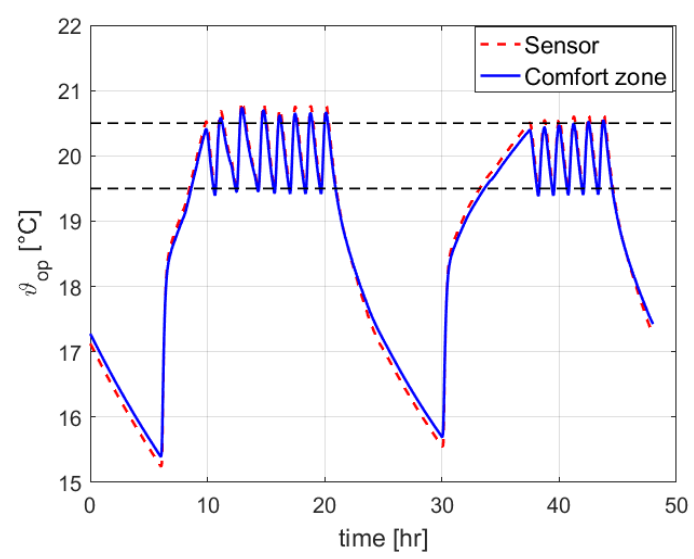

(b)

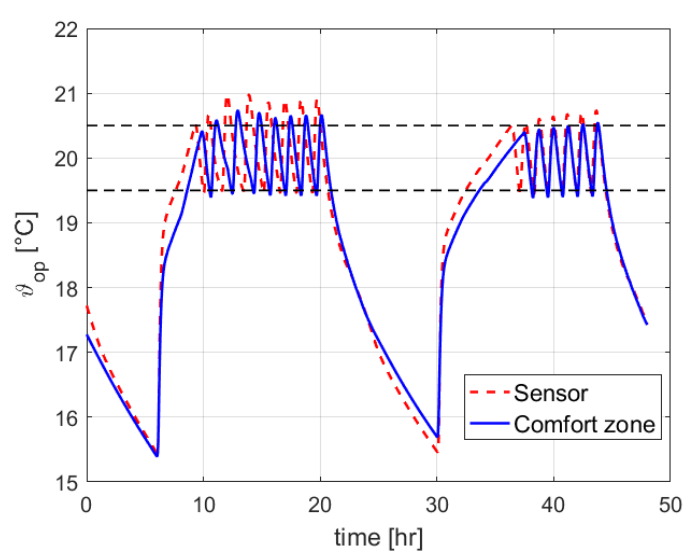

(c)

Fig.7. Comparison between the operative temperature of the comfort zone (solid line) and the operative temperature measured by the sensor (dashed line) in position A (a), B (b) and $\mathrm{C}$ (c) for two typical days of the winter.

As general conclusion, the room temperature sensor must be placed close to the emitters and far from the cold external walls, if possible. If not, it is possible to compensate the negative effects due to the proximity of the external wall and to the distance from the emitters by varying the setpoint of the operative temperature.

When the sensor is placed in position A, a significant overheating time is obtained. This can be reduced by reducing the setpoint from $20{ }^{\circ} \mathrm{C}$ to $19{ }^{\circ} \mathrm{C}$ (case Abis) and/or reducing the dead band from 1 to $0.5 \mathrm{~K}$ (case Atris).

In Table 3 the results obtained considering cases Abis (setpoint $19^{\circ} \mathrm{C}$, dead band $1 \mathrm{~K}$ ) and Atris (setpoint $19.25^{\circ} \mathrm{C}$ and dead band $0.5 \mathrm{~K}$ ), are collected. The results reported in Table 3 show that, even if lower set-point temperature (Abis) and restricted dead-band (Atris) can help to reduce the frequency of overheating conditions (halving $\tau_{\mathrm{oh}}$ with respect to the case with standard settings, see Table 2) the comfort time for both the cases is still less than $50 \%$, which is not acceptable.

Table 3. Comfort and heating system parameters for cases R1, with different thermostat settings.

\begin{tabular}{|l|c|c|c|c|c|c|}
\hline & $\begin{array}{c}\tau_{\mathrm{c}} \\
{[\%]}\end{array}$ & $\begin{array}{c}\tau_{\mathrm{oh}} \\
{[\%]}\end{array}$ & $\begin{array}{c}\mathrm{t}_{\text {on }} \\
{[\mathrm{min}]}\end{array}$ & $\begin{array}{c}\mathrm{t}_{\text {off }} \\
{[\mathrm{min}]}\end{array}$ & $\begin{array}{c}\mathrm{t}_{\text {on,y }} \\
{[\mathrm{hr}]}\end{array}$ & $\begin{array}{c}\mathrm{E} \\
{[\mathrm{kWh}]}\end{array}$ \\
\hline Abis & 45.5 & 42.3 & 647 & 768 & 2059 & 1516 \\
\hline Atris & 44.1 & 47.6 & 565 & 757 & 2051 & 1531 \\
\hline Cbis & 68.4 & 28.8 & 123 & 215 & 1490 & 1393 \\
\hline Ctris & 82.8 & 6.8 & 105 & 233 & 1353 & 1346 \\
\hline
\end{tabular}

On the contrary, if the sensor is in position $\mathrm{C}$, it is possible to find an adequate setpoint value by means of which comfort conditions in the room, similar to those obtained if the sensor is placed in B, are obtained.

This is confirmed by the results of case Ctris (setpoint temperature equal to $20.2{ }^{\circ} \mathrm{C}$, dead-band of $1 \mathrm{~K}$ ), reported in Table 3, for which the comfort time is $82.8 \%$, whilst in case B is $85.1 \%$ (see Table 2). Moreover, comparing the results collected in Table 2 and Table 3 a discrepancy between the energy demand for case B and Ctris around $2 \%$, due to the lower seasonal heating time $(-7 \%$ with respect to case $B)$ can be evidenced. Therefore, numerical results demonstrate that it is always possible to "tune" the sensor placed near to the radiator, as in the case of thermostatic valves, in order to obtain the same results that can be reached by the sensor in position B (ideal position).

\subsection{Cases R2: low temperature radiator}

In cases $R 2$, radiators are bigger than the previous cases ( 21 elements instead of 12) and fed by water with a lower temperature $\left(60^{\circ} \mathrm{C}\right.$ instead of $\left.80^{\circ} \mathrm{C}\right)$.

In Table 4 comfort and heating system parameters for cases $A, B$ and $C$ are reported.

If the sensor is placed in $\mathrm{A}$, the change of radiator size leads to a slight reduction of the frequency of overheating (around $-2 \%$ with respect to case R1) and, consequently, to an increment of the comfort time $(+2.6 \%$ with respect to case R1). However, despite this increment, comfort time is still too low, slight above $20 \%$ of the working time.

Table 4. Comfort and heating system parameters for cases R2.

\begin{tabular}{|c|c|c|c|c|c|c|}
\hline & $\begin{array}{c}\tau_{\mathrm{c}} \\
{[\%]}\end{array}$ & $\begin{array}{c}\tau_{\text {oh }} \\
{[\%]}\end{array}$ & $\begin{array}{c}\mathrm{t}_{\text {on }} \\
{[\mathrm{min}]}\end{array}$ & $\begin{array}{c}\mathrm{t}_{\text {off }} \\
{[\mathrm{min}]}\end{array}$ & $\begin{array}{c}\mathrm{t}_{\text {on,y }} \\
{[\mathrm{hr}]}\end{array}$ & $\begin{array}{c}\mathrm{E} \\
{[\mathrm{kWh}]}\end{array}$ \\
\hline$A$ & 21.4 & 77.9 & 741 & 736 & 2395 & 1583 \\
\hline$B$ & 83.2 & 7.0 & 143 & 292 & 1457 & 1342 \\
\hline$C$ & 69.1 & 4.6 & 101 & 234 & 1255 & 1280 \\
\hline
\end{tabular}


On the contrary, if the sensor is placed in position B and $\mathrm{C}$, the comfort time slightly decreases (from $-2 \%$ to $5 \%$ for cases $\mathrm{B}$ and $\mathrm{C}$ respectively), but it is still acceptable (above $69 \%$ of the working time). The adoption of a bigger radiator determines a decrease ($0.3 \%$ with respect to case R 1 ) of the frequency of overheating conditions if the sensor is located in B, whilst in case $C$ overheating conditions are more frequently $(+0.6 \%)$ with respect to case $\mathrm{R} 1$.

The mean heating time $\left(t_{o n}\right)$ increases $(+2 \%$ for position $\mathrm{A}$, around $+10 \%$ for $\mathrm{B}$ and $\mathrm{C})$. This increment of $t_{o n}$ with respect to cases $\mathrm{R} 1$ is due to the greater thermal inertia of the radiator, which slows the dynamic of the heating system. In addition, for the same reason an increase of the shutdown time $\left(t_{\text {off }}\right)$ is observed in case B and $C$. Again, this increase is related to the larger thermal inertia of the radiator; in this case the radiator continues to release energy to the zone when it is turned off, until a thermal equilibrium with the zone is achieved. On the contrary, if the sensor is in A, $t_{\text {off }}$ decreases of around $8 \%$. Since in almost all the cases an increment of both the mean heating and shutdown time are detected, the seasonal operating time is not affected by the radiator size: discrepancies with cases $\mathrm{R} 1$ are around the $1 \%$.

Finally, the adoption of bigger radiators, fed with lower water temperature leads to a reduction of $3 \%$ of the energy demand $(E)$, regardless the sensor position. It is possible to highlight that this energy demand does not take into account the heat generation system, so that the potential energy savings could be greater if heat pumps and condensing boilers are adopted, since these heat generators are characterised by improved performances in presence of low values of the radiator inlet or outlet water temperature, respectively.

\subsection{Cases FR}

Undercooling (i.e. operative temperature lower than $19.5^{\circ} \mathrm{C}$ ) like overheating are conditions that have to be prevented for assuring comfort feeling to the occupant. Both in cases R1 and R2, undercooling conditions mainly appears during the restart after the night. In fact, in critical conditions, one hour of preheating (from 6:00 to $7: 00$ ) is not enough to guarantee adequate comfort conditions at the beginning of the working time. This inconvenient can be overcame, in case $R 2$ in which radiators are sized for low inlet water temperature, imposing a high inlet water temperature during the restarts (if the operative temperature measured by the thermostat is under the lower bound of the dead band). This is possible if the radiators are coupled to gas boilers for which water temperature of $80^{\circ} \mathrm{C}$ is possible. On the contrary, this is not possible with conventional heat pumps able to guarantee a maximum water temperature of $55 / 62{ }^{\circ} \mathrm{C}$.

For each sensor position, the adoption of the fast restart control leads to a reduction of the frequency of undercooling, as it can be deduced from Table 5. In fact, the undercooling time can be deducted by the data quoted in Table 5 as the complement to unity of the sum of $\tau_{\mathrm{c}}$ and $\tau_{\mathrm{oh}}$.

Table 5. Comfort and heating system parameters for cases FR

\begin{tabular}{|c|c|c|c|c|c|c|}
\hline & $\begin{array}{c}\tau_{\mathrm{c}} \\
{[\%]}\end{array}$ & $\begin{array}{c}\tau_{\mathrm{oh}} \\
{[\%]}\end{array}$ & $\begin{array}{c}\mathrm{t}_{\mathrm{on}} \\
{[\mathrm{min}]}\end{array}$ & $\begin{array}{c}\mathrm{t}_{\text {off }} \\
{[\mathrm{min}]}\end{array}$ & $\begin{array}{c}\mathrm{t}_{\text {on,y }} \\
{[\mathrm{hr}]}\end{array}$ & $\begin{array}{c}\mathrm{E} \\
{[\mathrm{kWh}]}\end{array}$ \\
\hline$A$ & 6.9 & 92.7 & 683 & 791 & 2197 & 1646 \\
\hline$B$ & 86.3 & 6.5 & 102 & 238 & 1232 & 1345 \\
\hline$C$ & 69.4 & 4.6 & 70 & 192 & 1024 & 1282 \\
\hline
\end{tabular}

The data reported in Table 5 demonstrate that the impact of the fast restart control on the different parameters depends on the sensor position.

If the sensor is placed in $\mathrm{A}$, the reduction of the undercooling time is very limited. In fact, both considering small or big radiators (cases R1 and R2), the undercooling time is around $1 \%$, as inferred from Table 2 and Table 4.

Therefore, there is no need of this additional control that, on the contrary, leads to an increment of the overheating time, reducing the comfort time at $7 \%$ only. This is due to the high response time of the heating system, linked to the larger thermal inertia of the radiators, which forces radiators to provide the extra power every day for more than the first heating hour.

On the contrary, if the thermostat is in $\mathrm{B}$, the undercooling time is reduced from $10 \%$ to $7 \%$, increasing the comfort time.

Finally, if the sensor is in position $\mathrm{C}$, only a reduction of $0.4 \%$ (from $26.4 \%$ to $26 \%$ ) of the undercooling time is observed. The low impact of the fast restart control is due to the fact that undercooling, in this case, is mainly related to the position of the sensor, which is closer to the emitter than the comfort zone. However, modifying adequately the thermostat set-point, in order to obtain comfort conditions similar to those obtained in B, the fast restart control leads to an important reduction of the undercooling time.

Since during the restart the emitter releases an "extra" power due to the high temperature of the inlet water, the mean heating time $\left(t_{o n}\right)$ decreases in all the cases: for case $A$ the decrease is of $7.8 \%$ (from 741 to 683 minutes), whilst for cases $B$ and $C$ the decrement is around $30 \%$, with a mean heating time lower than two hours. Due to the significant overheating conditions that characterise cases with the sensor in position $\mathrm{A}$, the mean shutdown time $\left(t_{o f f}\right)$ in this case is greater than 13 hours, with an increment of $7.5 \%$ with respect to the case without the fast restart strategy. On the contrary, if the sensor is in position $\mathrm{B}$ and $\mathrm{C}$, shutdown time decreases of around $18 \%$. In addition, the adoption of the fast restart strategy determines the reduction of the seasonal heating time $\left(t_{o n, y}\right)$ which decreases of $8 \%, 15 \%$ and $18 \%$ for sensors located in A, B and C, respectively.

Finally, it would be expected that the adoption of the fast restart strategy, with the aim to increment the comfort conditions reducing the undercooling, would lead to an increment of the total energy demand. Comparing the results collected in Table 5 with those reported in Table 4, it is possible to appreciate that, if the sensor is in position $B$ and $C$, the energy demand increases only $0.2 \%$. On the contrary, if the sensor is 
located in A, the increment of the energy demand is more relevant $(+4 \%)$.

\section{Conclusions}

In this paper, the effects of the position of the room temperature sensor on the comfort and energy performances have been studied numerically. The adopted zonal model for the estimation of the air temperature distribution in the room in absence of forced convection has been described. The results of the numerical analysis by considering: (i) three different positions of the room temperature sensor (far from the emitter and close to a cold external wall, in the middle of the room and close to the emitter), (ii) two different strategies for emitter sizing and (iii) two different heating control strategies have shown that:

-If the temperature sensor is placed far from the emitter and close to a cold external wall significant overheating time can be observed in the room caused by the slow time response of the heating system;

-If the temperature sensor is close to the emitter, a tuning of the setpoint temperature enables to obtain similar comfort conditions achieved positioning the sensor in the middle of the room (ideal position);

- The use of a bigger radiators fed with low water temperature leads to a reduction of overheating time and of the energy demand, not depending on the sensor position;

-The adoption of the fast restart control in addition to the weather compensation causes a reduction of the frequency of undercooling and, consequently, an increase of the comfort conditions, except if the temperature sensor is far from the emitter and close to a cold wall;

- Regarding the energy consumption, the adoption of the fast restart control determines very slight increments compared to cases $R 2$.

As general recommendation, it must be avoided to place the room temperature sensor close to cold external walls far from the emitters, for guaranteeing adequate comfort conditions and heating system behaviour.

The numerical results presented in this paper demonstrates how dynamic energy simulation tools, like ALMABuild, greatly facilitate the work of the designers of HVAC systems, providing a series of detailed information about comfort conditions in the room and HVAC system behaviour which are difficult to obtain in other ways. Future works will investigate more accurately the influence of the temperature sensor position on the HVAC system behaviour by modelling the hydraulic loop between the emitters and the generator and the heat generation system, not considered in this paper.

\section{Reference}

1. Directive 2010/31/UE of the European Parliament and of the Council of 19 May 2010 on the energy performance of buildings (recast). L. 153/13, Official Journal of European Union, 18 June 2010

2. S.A. Klein, W.A. Beckman, J.W. Mitchell, J.A. Duffie, N.A. Duffie, T.L. Freeman. TRNSYS 17: $A$ Transient System Simulation Program. Madison, USA: Solar Energy Laboratory, University of Wisconsin. (2010)

3. D.B. Crawley, C.O. Pedersen, L.K. Lawrie, F.C. Winkelmann. Energy plus: Energy simulation program. ASHRAE Journal, 42.4: 49-56 (2000).

4. E. Wurtz, M. Musy L. Mora. Introduction of specific laws in zonal model to describe temperature fields and air flow patterns in mixed ventilated buildings. Journal of the Human-Environment System, 3.1: 43-59. (1999)

5. C. Inard, H. Bouia, P. Dalicieux. Prediction of air temperature distribution in buildings with a zonal model. Energy and Buildings, 24.2: 125-132 (1996)

6. E. Wurtz, F. Deque, L. Mora, E. Bozonnet, S. Trompezinsky. SIM_ZONAL: a software to evaluate the risk of discomfort: coupling with an energy engine, comparison with CFD codes and experimental measurements. Proc. Building Simulation 3: 1423-1428 (2003)

7. E. Wurtz, L. Mora C. Inard. An equation-based simulation environment to investigate fast building simulation. Building and Environment, 41.11:15711583. (2006)

8. A.C. Megri,Y. Yu. New calibrated zonal model (POMA + ) for temperature and airflow predictions. Building and Environment, 94.1:109-121 (2015)

9. A. Daoud, N. Galanis, O. Bellache. Calculation of refrigeration loads by convection, radiation and condensation in ice rinks using a transient $3 \mathrm{D}$ zonal model. Applied Thermal Engineering, 28.14: 17821790 (2008)

10. J.P. Campana, M. Magni, M. Dongellini, G.L. Morini. The benchmark of a new SIMULINK library for thermal dynamic simulation of buildings. Proceedings of $3^{\text {rd }}$ Building Simulation Applications conference (2017)

11. M. Magni, J.P. Campana, G.L. Morini. Dynamic simulations as a tool for the analysis of the interactions among the controllers of HVAC systems. Proceedings of $3^{\text {rd }}$ Building Simulation Applications conference (2017)

12. C. Wemhöner, B. Hafner and K. Schwarzer. Simulation of solar thermal systems with CARNOT blockset in the environment Matlab Simulink. Proceedings Eurosun 2000, 2000

13. R.K. Rajput. Heat and Mass Transfer.Tata McGrawhill (1999)

14. M. Magni, J.P. Campana, F. Ochs, G.L. Morini. Numerical investigation of the influence of heat emitters on the local thermal comfort in a room. Building Simulation. DOI:10.1007/s12273-0.190506-8. 